REFLEKSI HUKUM

Jurnal Ilmu Hukum
p-ISSN 2541-4984 | e-ISSN 2541-5417

Volume 2 Nomor 1, Oktober 2017, Halaman 51 - 64

DOI: https://doi.org/10.24246/jrh.2017.v2.i1.p51-64

Open access at: http://ejournal.uksw.edu/refleksihukum

Penerbit: Fakultas Hukum Universitas Kristen Satya Wacana

\title{
PENDEKATAN DAN STRATEGI NEGOSIASI DALAM NORMALISASI HUBUNGAN DIPLOMATIK AMERIKA SERIKAT - KUBA
}

\author{
Arie Siswanto \\ Fakultas Hukum Universitas Kristen Satya Wacana \\ Korespondensi: arie.siswanto@staff.uksw.edu
}

\begin{abstract}
Abstrak
Sengketa berkepanjangan antara Amerika Serikat dengan Kuba merupakan sengketa peninggalan era Perang Dingin yang hingga sekarang belum terselesaikan secara tuntas, meskipun kedua negara sudah saling menjalin kembali hubungan diplomatik yang sempat terputus. Tulisan ini berisi analisis tentang faktor-faktor yang mempengaruhi negosiasi internasional antara AS dan Kuba, yang mencakup baik faktor penghambat maupun faktor pendukung, dengan bertumpu pada dua aspek negosiasi yaitu pendekatan dan teknik negosiasi. Berdasarkan profil sengketa yang ada, pendekatan integratif merupakan pendekatan yang paling sesuai untuk menyelesaikan sengketa di antara kedua negara. Sementara itu orientasi ke masa depan dan penekanan pada kepentingan bersama merupakan teknik negosiasi yang seharusnya dielaborasikan oleh kedua pihak yang bersengketa guna menyelesaikan sengketa mereka secara progresif.
\end{abstract}

Kata-kata kunci: penyelesaian sengketa internasional; negosiasi; pendekatan integratif.

\begin{abstract}
The prolonged dispute originated from the Cold War era between the United States and Cuba has not been completely resolved yet, even after the two countries have re-established diplomatic ties. This paper discusses the factors affecting the on-going international negotiations between the US and Cuba, which include both constraining as well as supporting factors, based on two aspects of negotiation, namely approach and negotiation techniques. Based on the profile of the dispute, it is argued that integrative approach is the most appropriate approach to resolve disputes between the two countries. Meanwhile, future oriented process and emphasis on mutual interests are negotiation techniques that should be elaborated by both disputing parties in order to settle their dispute progressively.
\end{abstract}

Keywords: international dispute resolution; negotiation; integrative approach. 


\section{PENDAHULUAN}

Berbeda dari struktur hukum nasional yang mengenal keberadaan pemerintah sebagai representasi kedaulatan yang berada di atas subyeksubyek hukumnya, hukum internasional secara umum masih memiliki struktur koordinatif yang ditandai oleh tidak adanya organ yang berada di atas negara-negara sebagai subyek utama hukum internasional. Dengan struktur seperti ini, ada dua hal yang menjadi sangat penting dalam wacana hukum internasional.

Pertama, suka atau tidak, ketiadaan otoritas di atas negara memunculkan kondisi di mana sarana-sarana selfhelp menjadi sangat relevan. Tanpa ada otoritas yang memiliki wewenang yang jelas untuk memaksakan hukum internasional, negara-negara terpaksa lebih sering melakukan upaya-upaya sendiri untuk memperjuangkan kepentingan dalam hubungan dengan negaranegara lain. Kedua, pengelolaan sengketa antar-negara juga secara khusus memiliki makna yang penting, untuk menjaga agar sengketa antar-negara yang selalu berpeluang untuk terjadi tidak berkembang sedemikian rupa hingga mengancam hubungan negaranegara yang terkait. Dalam kategori yang sama, mekanisme penyelesaian sengketa antar-negara juga menjadi sangat krusial. Itu sebabnya, meskipun tidak memiliki konten normatif yang kental, penyelesaian sengketa internasional (settlement of international disputes) menjadi salah satu pokok bahasan penting dalam diskursus hukum internasional.

Salah satu sengketa antar-negara yang menarik untuk diamati adalah sengketa antara Amerika Serikat (AS) dan Kuba yang berujung pada putusnya hubungan diplomatik di antara dua negara bertetangga itu. Sengketa ini menjadi menarik karena di samping merupakan peninggalan Perang Dingin, juga karena eskalasinya sedemikian serius hingga sempat memunculkan kekhawatiran akan pecahnya Perang Dunia III.

Kini, era Perang Dingin telah lewat menyusul runtuhnya Uni Soviet sebagai patron state di kubu negara-negara komunisme. Meski begitu, lebih dari dua puluh tahun sejak berakhirnya Perang Dingin, hubungan diplomatik di antara Amerika Serikat dan Kuba belum bisa dikatakan pulih sepenuhnya, meskipun perundingan di antara kedua negara diselenggarakan secara cukup intens. Baru pada tahun 2015 secara formal hubungan antara AS dan Kuba mulai pulih.

Tulisan ini bermaksud mengkaji faktor-faktor yang mempengaruhi perundingan normalisasi hubungan diplomatik antara Amerika Serikat dan Kuba. Dengan 'faktor-faktor yang mempengaruhi', yang dicakup dalam tulisan ini adalah faktor pendorong maupun penghambat perundingan. Agar terfokus, kajian akan dilakukan pada dua aspek perundingan, yaitu pendekatan perundingan (negotiation approach) dan strategi perundingan (negotiating strategy) yang diimplemen- 
tasikan oleh kedua pihak yang berselisih.

\section{PEMBAHASAN}

\section{Latar Belakang Sengketa AS - Kuba}

Di tengah-tengah berkecamuknya Perang Dingin yang diwarnai oleh pertarungan ideologis antara Blok Barat (AS dan sekutunya) dan Blok Timur (Uni Sovyet dan sekutunya), pada tahun 1959 terjadi revolusi di Kuba yang mengantarkan rezim komunis ke tampuk kekuasaan di negara itu. Bagi AS pergantian rezim di negara tetangganya itu memunculkan kekhawatiran yang mendalam. Pergeseran kekuasaan ke tangan rezim komunis di Kuba dianggap sebagai dinamika yang membahayakan kepentingan AS. Jarak geografis dengan Kuba yang tidak terlalu jauh memunculkan kondisi di mana AS terpapar pada ancaman serangan dari kubu Uni Sovyet.

Dalam perkembangan selanjutnya, pergantian rezim di Kuba menyebabkan memburuknya hubungan di antara AS dan Kuba. Puncaknya terjadi ketika pada tahun 1961 AS memutuskan hubungan diplomatik dengan Kuba dan mulai melancarkan aksi militer terselubung atau tidak langsung untuk menjatuhkan rezim komunis di Kuba. Sebagai reaksi, Kuba kemudian melakukan nasionalisasi terhadap aset-aset perusahaan AS di Kuba. ${ }^{1}$ Tindakan
Kuba ini membuat AS bereaksi dengan menerapkan embargo dan laranganlarangan yang ditujukan terhadap Kuba, sehingga hubungan di antara keduanya menjadi semakin buruk.

Salah satu insiden serius yang kemudian memperburuk hubungan kedua negara adalah Invasi Teluk Babi (Bay of Pigs invasion) yang dilancarkan AS pada tahun 1961 untuk menggulingkan rezim komunis Kuba di bawah Fidel Castro.

Intervensi militer AS di Kuba ini dengan segera memicu nasionalisme warga Kuba dan memunculkan sikap antipati terhadap AS di seantero Kuba. Peristiwa ini juga menjadi bumerang bagi AS setelah kemudian Kuba mengizinkan Uni Sovyet memasang instalasi peluru kendali di Kuba, yang jaraknya kurang dari 100 mil dari pantai AS.

Setelah lebih dari sepuluh tahun tanpa hubungan bilateral formal, pada tahun 1977 dalam masa kepresidenan Jimmy Carter, AS dan Kuba menandatangani perjanjian untuk saling membuka "interest section" di Havana (US Interest Section) dan di Washington, DC (Cuba Interest Section). Di Havana, US Interest Section yang mengurusi kepentingan AS di Kuba ini beroperasi di bawah naungan Kedutaan Besar Swiss. ${ }^{2}$

Perang Dingin pada akhirnya usai pada tahun tahun 1990-an. Namun usainya Perang Dingin tidak dengan sendirinya membuat hubungan AS -

Greg Ryan, US Foreign Policy towards China, Cuba and Iran - The Politics of Recognition Routledge (2017) 82. Kevin J. Fandl, 'Adios Embargo: the Case for Executive Termination of the U.S. Embargo on Cuba' (2016) SSRN.

2 US Embassy in Cuba, https://cu.usembassy.gov/our-relationship/policy-history/embassy-factsheets/dikunjungi pada hari Jumat, 25 Agustus 2017, pk. 10.18 WIB. 
Kuba membaik. Meskipun berbagai pihak, termasuk Dewan Keamanan PBB, mendorong agar AS mengakhiri embargonya terhadap Kuba, AS masih tetap bersikukuh melanjutkan kebijakan embargonya terhadap Kuba. Hubungan antara AS dan Kuba memasuki babak baru ketika pada tanggal 17 Desember 2014 Presiden AS Barack Obama dan Presiden Kuba Raúl Castro mendeklarasikan dimulainya proses normalisasi hubungan antara AS dan Kuba, yang oleh media dijuluki sebagai "Mencairnya Kuba" ("the Cuban Thaw"). Deklarasi itu kemudian diikuti oleh serangkaian perundingan tertutup (closed negotiation) yang diselenggarakan di Kanada dan Vatikan. Dengan peran aktif Paus Fransiskus sebagai penengah, ${ }^{3}$ secara bertahap kedua negara menyepakati pelonggaran beberapa pembatasan dan embargo AS, termasuk pelonggaran pembatasan perjalanan (travel restrictions), transfer uang dan akses perbankan AS ke dalam sistem keuangan Kuba.

Selanjutnya, secara bertahap pemulihan hubungan di antara kedua negara juga sampai pada keputusan AS dan Kuba untuk saling membuka kembali kedutaan masing-masing pada tanggal 20 Juli 2015. Kemudian, pada bulan Desember 2015, Presiden Obama mengumumkan bahwa AS akan memulai perundingan guna memulihkan hubungan diplomatik secara penuh dengan Kuba. Pada tanggal 20 Maret 2016 Presiden Barack
Obama mengunjungi Kuba dan menjadi presiden AS pertama yang mengunjungi Kuba setelah 88 tahun.

\section{Profil Negosiasi AS - Kuba}

Salah satu faktor yang dominan dalam negosiasi dalam kerangka pemulihan hubungan diplomatik antara AS dan Kuba adalah sikap tidak percaya (distrust) di pihak Kuba terhadap AS sebagai akibat tindakan intervensi AS terhadap Kuba dalam peristiwa Invasi Teluk Babi tahun 1961. Tindakan intervensi AS terhadap Kuba telah memunculkan anggapan bahwa AS bukanlah mitra perundingan yang jujur. Sikap ini sedikit-banyak ikut menentukan jalannya negosiasi yang diselenggarakan di antara kedua negara baik sebelum maupun pascapemulihan hubungan diplomatik.

Pada awalnya, sifat tertutup negosiasi yang diselenggarakan antara AS dan Kuba yang berujung pada pengumuman Presiden Obama tentang kesiapan AS memulihkan hubungan diplomatik secara penuh dengan Kuba pada bulan Desember 2015 memunculkan optimisme bahwa pemulihan hubungan tersebut akan terjadi dalam waktu dekat. Namun, ketika delegasi AS mengadakan perundingan dua hari dengan Kuba pada awal bulan Januari 2016, tampak jelas bahwa negosiasi diwarnai oleh sikap tidak percaya (distrust) serta hambatan kultural. Sikap masing-masing pihak dalam

3 Daniel H. Levine, 'What Pope Francis Brings to Latin America' (2016) Center for Latin American \& Latino Studies, 7. 
arena publik pun berkontribusi terhadap sulitnya negosiasi. Presiden Obama secara terbuka menyatakan bahwa agar pemulihan hubungan diplomatik secara penuh dapat diwujudkan, Kuba harus memenuhi syarat yang diminta AS dalam beberapa bidang penting, termasuk pencabutan larangan bagi para diplomat AS untuk melakukan perjalanan di wilayah Kuba. Oleh Kuba, pernyataan ini dianggap kurang patut karena mencerminkan arogansi AS yang hendak memaksakan syarat-syarat perundingan secara sepihak. Sebaliknya, Kuba pun tidak terlalu menunjukkan antusiasme dalam perundingan. Secara hati-hati para pejabat Kuba cenderung menghindari istilah "normalisasi hubungan dengan AS." Alih-alih, mereka lebih sering menggunakan istilah "mengadakan hubungan diplomatik lagi dengan AS." Selain itu, kebijakan AS untuk memberikan status sebagai penduduk yang sah (legal resident) bagi imigran Kuba dianggap sebagai ganjalan oleh Kuba. Hal lain yang juga menjadi hambatan perundingan adalah kebijakan AS yang selama ini memasukkan Kuba dalam daftar negara pendukung terorisme. Kuba meminta agar status Kuba tersebut direvisi. Sebagai tambahan, Kuba juga meminta agar AS mengakhiri embargo atas Kuba, termasuk larangan bagi warga AS untuk berwisata ke Kuba.

Alih-alih melunak, posisi masingmasing negara bahkan cenderung mengeras pada akhir perundingan dua hari tersebut. Dari sisi Kuba, ada dua hal yang dikatakan tidak mungkin dinegosiasikan (non-negotiable issues). Pertama, Kuba tidak akan pernah bersedia menyerahkan buronan AS yang mendapatkan suaka di Kuba. Kedua, Kuba juga tidak akan mencabut larangan bepergian bagi diplomat AS di Kuba jika AS tetap mendukung para dissident (pembangkang) yang menentang pemerintah Kuba. Bahkan, beberapa hari setelah perundingan yang kurang berhasil, Presiden Kuba Raúl Castro menekankan bahwa Kuba hanya akan mempertimbangkan normalisasi hubungan dengan AS secara penuh kalau AS memenuhi tiga syarat, yaitu:

a) mengembalikan pangkalan militer AS di Teluk Guantanamo kepada Kuba;

b) mengakhiri embargo perdagangan atas Kuba; dan

c) memberikan kompensasi untuk kerugian ekonomi dan kemanusiaan yang ditimbulkan sebagai akibat penerapan embargo.

Dari sisi AS, syarat-syarat tersebut tidaklah mudah untuk dipenuhi. Pangkalan militer AS di Teluk Guantanamo memiliki nilai strategis yang sangat penting dalam kerangka pertahanan AS, sehingga melepaskan Guantanamo akan membuat AS semakin terpapar pada serangan militer dari Kuba. Sementara itu pengakhiran embargo perdagangan justru menjadi kartu truff AS untuk menggiring Kuba melakukan apa yang diminta oleh AS, sehingga AS tidak akan mengubah 
kebijakan embargonya sebelum Kuba memenuhi permintaan AS. Demikian pula, syarat pemberian kompensasi akibat embargo juga sulit dipenuhi karena bagi AS syarat ini akan menempatkan AS sebagai pihak yang salah sehingga harus menanggung beban ganti kerugian.

\section{Analisis terhadap Pendekatan dan Strategi Negosiasi AS - Kuba}

Secara teoretik ada empat jenis pendekatan negosiasi (negotiation approach), yaitu pendekatan distributif (win-lose approach), pendekatan kalahkalah (lose-lose approach), pendekatan kompromi (compromise approach) dan pendekatan integratif (win-win approach). ${ }^{4}$

Pendekatan distributif juga dikenal dengan istilah lain, yaitu pendekatan kompetitif, zero-sum, atau valueclaiming. Menurut Walton \& McKersie (1968), dalam pendekatan distributif pihak yang bernegosiasi berupaya untuk mencapai tujuan yang bertentangan dengan tujuan pihak lawan negosiasi. ${ }^{5}$ Dengan demikian, karena tujuan yang hendak dicapai oleh para pihak dalam negosiasi saling bertentangan, tercapainya tujuan salah satu pihak dalam negosiasi hanya akan bisa dilakukan di atas kegagalan pihak lain mencapai tujuannya sendiri.

Pendekatan kalah-kalah umumnya diterapkan ketika satu pihak dalam negosiasi tidak dapat memperoleh tujuan perundingan, namun pada saat yang sama juga tidak menginginkan pihak lawannya untuk menang. Akibatnya, pihak yang merasa tidak mungkin menang dalam negosiasi akan melakukan berbagai langkah untuk menghalangi pihak lawan meraih apa yang menjadi tujuannya.

Pendekatan kompromis diterapkan ketika para pihak dalam negosiasi menyadari bahwa mereka akan berada dalam situasi lose-lose apabila secara rigid tetap berorientasi pada tujuan masing-masing, sehingga untuk menghindari situasi tersebut pihak-pihak dalam negosiasi saling menurunkan target negosiasi.

Pendekatan integratif, pendekatan kolaboratif atau value-creating adalah pendekatan negosiasi di mana pihakpihak dalam negosiasi mencoba mencapai tujuan yang tidak secara fundamental berbeda dari lawan negosiasi sehingga tujuan masingmasing pihak dapat diintegrasikan dan dapat dicapai oleh masing-masing pihak tanpa membuat pihak lain kalah. Pendekatan ini juga dikenal dengan istilah pendekatan win-win, karena tidak ada pihak yang sepenuhnya kalah.

Di antara keempat pendekatan tersebut, pendekatan integratif merupakan pendekatan yang dianggap ideal karena secara umum dipandang lebih produktif untuk menghasilkan

http://www.managementstudyhq.com/approaches-to-negotiation.html, dikunjungi pada hari Sabtu, 9 Desember 2017, pk. 09.52 a.m. WIB.

5 Nimet Beriker-Atiyas, 'An Analysis of Integrative Outcomes in the Dayton Peace Negotiations' (nd) (2000) 11 The International Journal of Conflict Management 11, 360. 
kesepakatan di antara pihak-pihak yang berunding. Dalam negosiasi pemulihan hubungan diplomatik antara AS dan Kuba, pendekatan integratif ini juga menjadi pendekatan yang paling ideal, meskipun tidak berarti bahwa pendekatan ini mudah untuk diterapkan.

Sebagaimana diuraikan dalam bagian sebelumnya, perselisihan antara AS dan Kuba sangat didominasi oleh sikap ketidakpercayaan (distrust), terutama dari pihak Kuba kepada AS. Kondisi ini, ditambah fakta bahwa perselisihan di antara kedua negara itu sudah berlangsung cukup lama (lebih dari 80 tahun), secara psikologis membuat keduanya sulit untuk menghilangkan stigma masing-masing sebagai musuh dan ancaman (threat). Kondisi inilah yang menyebabkan perundingan selama dua hari yang diselenggarakan pada bulan Januari 2016 diwarnai oleh sikap keras kedua belah pihak yang bersikukuh untuk memaksakan kehendak masing-masing. Sikap hostile yang masih membayangi kedua negara bahkan juga membuka peluang bagi ditempuhnya pendekatan loselose oleh kedua belah pihak karena faktor prestige and pride. Kalau ini terjadi, upaya pemulihan hubungan secara penuh di antara kedua negara ini tentu akan menjadi semakin sulit.

Pendekatan win-win berpeluang untuk diterapkan dalam negosiasi pemulihan hubungan diplomatik AS - Kuba mengingat bahwa kedua negara sebenarnya saling membutuhkan. Kuba, yang sejak tahun 1962 mengalami tekanan akibat embargo ekonomi AS, memerlukan akses terhadap lembaga-lembaga keuangan dan perdagangan internasional. Kebutuhan ini antara lain tampak dari kebijakan regulasi penanaman modal asing Kuba yang sejak tahun 2014 menunjukkan keinginan negara tersebut untuk mengakses pasar global. ${ }^{6}$ Di sisi lain, dari perspektif AS terbukanya pasar Kuba juga akan memberikan manfaat bagi perusahaan-perusahaan AS. Dengan demikian, kepentingankepentingan AS maupun Kuba pada titik ini tidaklah saling bertentangan melainkan justru bersifat saling melengkapi. Ketika AS mengendorkan embargo ekonomi atas Kuba, Kuba tentu diuntungkan karena akan memiliki akses terhadap lembaga-lembaga ekonomi/keuangan internasional yang bisa mendorong pertumbuhan ekonominya, sedangkan pelakupelaku usaha AS pada gilirannya juga akan memiliki akses terhadap pasar Kuba yang menguntungkan. Kepentingan bersama (mutual interests) inilah yang semestinya bisa dielaborasi untuk mengembangkan pendekatan integratif dalam negosiasi. Dalam negosiasi AS - Kuba, penekanan pada profitabilitas ekonomi ini akan membuka peluang yang cukup besar mengingat bahwa selain kepentingan yang bersifat artifiasial (prestige and pride), sejak berakhirnya Perang Dingin tidak

Ben Birnbaum, et al., 'United States-Cuba Relations: Policy Recommendations to Advance Normalization' (2016) Graduate Policy Workshop Report, 16. 
ada kepentingan lain, termasuk kepentingan ideologis, yang setara dengan kepentingan ekonomi.

Berpijak pada linimasa historisnya, perselisihan antara AS - Kuba merupakan perselisihan yang cukup rumit. Kerumitan ini muncul karena dua hal. Pertama, perselisihan ini mencakup skala yang cukup luas dalam arti ada berbagai aspek yang menjadi bidang perselisihan, mulai dari persoalan embargo ekonomi, aspek kedaulatan wilayah (Guantanamo), hak asasi manusia dan politik. Kedua, perselisihan ini juga didominasi oleh sikap ketidakpercayaan salah satu pihak (Kuba) terhadap AS dan sikap AS yang menganggap Kuba sebagai musuh dan ancaman (negara pendukung terorisme). Oleh karena itu, perlu diterapkan strategi negosiasi yang tepat untuk merespons kedua hal tersebut. Bertitiktolak dari karakterisitik sengketa antara AS Kuba, ada empat aspek strategis yang perlu diperhatikan dalam negosiasi AS - Kuba agar membawa hasil yang positif. Aspek-aspek strategis tersebut meliputi langkah-langkah berikut:

a) Menumbuhkan kepercayaan di antara kedua belah pihak (developing trust)

Menumbuhkan kepercayaan merupakan strategi yang penting dalam upaya penyelesaian perselisihan yang diwarnai oleh ketidakpercayan (distrust) seperti dalam sengketa AS - Kuba ini. Sikap tidak mempercayai lawan negosiasi ini bisa membuat sebuah perundingan gagal, bahkan sebelum perun- dingan dimulai. Oleh karena itu, dalam sengketa AS - Kuba ini menumbuhkan sikap saling percaya di antara pihak-pihak yang bernegosiasi merupakan conditio sine qua non. Sebelum negosiasi dimulai dan selama negosiasi berlangsung, pihak-pihak yang bernegosiasi harus saling menunjukkan bahwa mereka masing-masing beritikad baik dalam menempuh negosiasi. Ini berarti bahwa pejabat negara AS maupun Kuba harus menunjukkan sikap menganggap masing-masing pihak sebagai mitra, bukan lawan. Untuk itu ada tiga hal yang diperlukan. Pertama, pejabat-pejabat negara, khususnya di ranah publik harus menghindari pernyataan-pernyataan yang bersifat hostile (bermusuhan) dan menyerang pihak lain. Kedua, baik AS maupun Kuba harus mulai saling memberikan konsesi untuk hal-hal sederhana yang dirasa dapat diberikan kepada lawan tanpa harus dinegosiasikan. Langkah ini penting karena betapapun konsesi yang diberikan tergolong kecil, setidaknya langkah ini akan mengirimkan pesan yang jelas tentang itikad baik pihak-pihak yang bernegosiasi. Ketiga, masingmasing pihak juga harus menahan diri untuk mengemukakan target perundingan di ranah publik yang akan mempersulit negosiasi, karena aspek pride and prestige bisa muncul ketika target negosiasi 
disampaikan kepada publik internasional.

Berghoff \& Fieweger mengemukakan bahwa upaya mengembangkan kepercayaan ini bisa dilakukan melalui penentuan tempat negosiasi, bagaimana negosiasi dilakukan dan bagaimana komunikasi dijalin selama negosiasi. ${ }^{7}$ Dalam negosiasi AS - Kuba, pilihan tempat tampaknya sudah dilakukan dengan baik, yakni di Kanada dan Vatikan. Vatikan secara khusus memberikan iklim negosiasi yang kondusif karena meskipun Kuba menganut komunisme, secara tradisional historis negara ini memiliki akar Katolisisme yang kuat, sehingga pemilihan Vatikan sebagai tempat negosiasi akan mendorong terciptanya kepercayaan. Untuk negosiasi masingmasing pihak juga harus memilih orang-orang yang bisa meyakinkan lawan negosiasi tentang perlunya perundingan dilakukan sampai membawa hasil positif bagi kedua belah pihak. Kemampuan negosiator untuk berkomunikasi dalam konteks kultural lawan negosiasi juga menjadi hal yang tidak bisa diabaikan, mengingat bahwa sebelumnya faktor kultural ini sempat membuat negosiasi tidak berhasil.

b) Berorientasi pada masa depan (future-oriented)
Putusnya hubungan diplomatik antara AS dan Kuba terjadi melalui beberapa peristiwa kritis dalam hubungan kedua negara, mulai dari invasi AS di Teluk Babi (1961), dukungan AS terhadap kelompok dissident penentang pemerintah di Kuba, krisis peluru kendali Kuba (1962), embargo ekonomi terhadap Kuba, perampasan aset AS dan warga negara AS di Kuba serta status pengungsi Kuba di AS.

Orientasi yang diperlukan dalam perundingan pemulihan hubungan diplomatik AS - Kuba adalah orientasi yang tertuju ke masa depan (future-oriented). Orientasi seperti ini amat penting untuk mendukung keberhasilan negosiasi karena orientasi ke masa depan membuat para pihak yang bernegosiasi lebih fokus pada apa yang hendak mereka raih (what will be achieved), ketimbang pada apa yang telah mereka alami (what has been experienced). Dalam hal ini, Barry Hart mengatakan bahwa orientasi pada masa depan akan membuka peluang bagi para pihak, "to engage in discussion in ways that reflect a level of respect and trust that helps empowers them to envision together a different future." Apa yang dikemukakan oleh Hart tentang "a different future" ini berkaitan erat dengan aspek berikut-

Ethan A. Berghoff \& Michael J. Fieweger (eds.), The International Negotiations Handbook: Success Through Preparation, Strategy, and Planning (Baker \& McKenzie - PILPG, nd) 28.

8 Mauro Galluccio, Handbook of International Negotiation - Interpersonal, Intercultural, and Diplomatic Perspectives (Springer 2015) 93. 
nya, yaitu perlunya mengedepankan kepentingan bersama (common interest).

c) Mengedepankan kepentingan bersama (common interest)

Pemulihan hubungan diplomatik secara penuh antara AS dan Kuba sesungguhnya bisa membawa dampak positif bagi kedua negara. Kalau hubungan diplomatik bisa dinormalisasikan, kedua negara akan bisa berinteraksi secara normal pula. Penghentian embargo ekonomi terhadap Kuba akan memungkinkan negara itu mengakses pasar global dan institusi-institusi keuangan internasional seperti Bank Dunia dan IMF secara penuh. Situasi ini membawa keuntungan bagi Kuba karena menyediakan sumber daya pembiayaan pembangunan yang memadai. Selain itu, bisa dipastikan bahwa Kuba juga akan memperoleh banyak pendapatan dari sektor pariwisata yang dari jumlah wisatawan dari AS diprediksi bisa meningkat hingga lima kali lipat. ${ }^{9}$

Sebaliknya, keterbukaan pasar Kuba dan integrasi Kuba dengan sistem perdagangan dan ekonomi global juga menyediakan peluangpeluang baru bagi pelaku-pelaku usaha AS. Kuba akan menjadi pasar yang terbuka dan menarik bagi para produsen AS sekaligus bisa menjadi sumber alternatif bagi berbagai kebutuhan masyarakat AS.

Aspek inilah yang semestinya mendapatkan penekanan lebih besar dalam negosiasi antara Kuba dan AS. Meski demikian, tetap harus disadari bahwa perselisihan AS Kuba sudah cukup akut dan mencakup bidang yang ekstensif mulai dari ekonomi, kultural, ideologi, sosio-politik, hak asasi manusia hingga isu keamanan dan kewilayahan. Dalam bidang-bidang ini posisi AS dan Kuba bisa sangat berbeda, bahkan berlawanan secara diametral. Misalnya, terkait dengan isu Guantanamo, Kuba menghendaki agar pangkalan AS di Kuba itu diserahkan kembali kepada Kuba, namun AS menolak. Demikian juga dalam kaitannya dengan isu kompensasi terkait nasionalisasi Kuba terhadap aset AS dan warga negara AS. Amerika Serikat menghendaki agar Kuba memberikan ganti rugi terhadap aset-aset yang pernah dirampas, namun Kuba cenderung menolak.

Penekanan terhadap common interest dan mutual benefit dalam bidang ekonomi dimaksudkan untuk mendorong agar AS dan Kuba lebih mengutamakan pendekatan value-creating ketimbang value-claiming yang tidak akan produktif bagi proses perundingan selanjutnya.

Emily Morris 'How will US - Cuba Normalization Affect Economic Policy in Cuba?' dalam Eric Hershberg \& William M. LeoGrande (eds.), A New Chapter in US-Cuba Relations Social, Political, and Economic Implications (Palgrave-MacMillan 2016) 116. 
d) Pentahapan perundingan untuk menghindari isu-isu sensitif yang bisa menghambat kesepakatan (avoiding deal-breakers)

Aspek berikutnya terkait dengan strategi negosiasi AS - Kuba adalah perlunya menghindari deadlock dalam perundingan. Patut disayangkan bahwa AS maupun Kuba telah sama-sama meletakkan batas yang tidak bisa dilampaui dalam negosiasi. Baik AS maupun Kuba secara terbuka sudah mengindikasikan hal-hal apa saja yang tidak bisa dinegosiasikan (nonnegotiable). Situasi ini kurang menguntungkan karena ketika target dan batas negosiasi sudah diketahui oleh publik, persoalan harga diri dan konsistensi menjadi unsur yang harus dipertimbangkan. Ketika Kuba, misalnya, sudah menyatakan secara terbuka bahwa pemulihan hubungan diplomatik secara penuh dengan AS hanya bisa diwujudkan jika AS mengembalikan Guantanamo kepada Kuba, demi harga diri dan konsistensi, Kuba akan cenderung menganggap syarat tersebut sebagai titik mati yang tidak bisa dinegosiasikan (non-negotiable). Hal yang sama terjadi ketika misalnya AS secara terbuka mensyaratkan pencabutan larangan bepergian bagi diplomat AS di Kuba, negara itu untuk alasan yang sama akan menganggap syarat tersebut sebagai non-negotiable. Secara teoretik, ketika telah disampaikan secara terbuka kepada publik, syarat-syarat tersebut telah tertransformasikan menjadi faktorfaktor yang berpotensi menggagalkan perundingan (deal-breaker). Besar kemungkinan perundingan akan menemui jalan buntu ketika masing-masing pihak bersikukuh membahas deal-breakers tersebut. Pada titik inilah strategi yang keempat menunjukkan relevansinya. Strategi keempat menyangkut pentahapan perundingan di mana pihak-pihak yang berunding untuk sementara waktu tidak mengagendakan non-negotiable conditions, melainkan memfokuskan diri pada perundingan untuk isu-isu yang memang masih bisa dinegosiasikan (negotiable issues). Dengan strategi ini diharapkan kesepakatan-kesepakatan yang dapat dicapai dalam bidang-bidang yang dapat dirundingkan secara perlahan-lahan akan mendorong terwujudnya fleksibilitas sikap di antara AS dan Kuba tentang isu-isu yang sebelumnya dianggap non-negotiable. Persoalan artifisial terkait harga diri dan konsistensi pada gilirannya juga akan terkelola dengan baik ketika masing-masing pihak secara mutual saling memberikan konsesi, sehingga tidak ada pihak yang merasa kalah.

\section{PENUTUP}

Sengketa yang terjadi antara AS Kuba merupakan contoh dari sengketa berskala luas yang mencakup berbagai 
aspek seperti, politik, ideologi, ekonomi, sosial dan bahkan budaya. Luasnya skala sengketa telah membuat upayaupaya penyelesaian sengketa melalui negosiasi menjadi sangat sulit. Hal ini terbukti dari kegagalan negosiasi pasca-pemulihan hubungan diplomatik antara AS - Kuba yang belum bisa membawa hasil yang diharapkan. Selain itu, sikap tidak percaya pada lawan perundingan juga menjadi faktor signifikan dalam menghambat negosiasi. Untuk itu, menumbuhkan kepercayaan (developing trust) merupakan strategi yang harus diterapkan agar perundingan bisa berlanjut dan membawa hasil positif bagi kedua negara. Pentahapan perundingan (negotiation staging) juga relevan untuk diterapkan mengingat bahwa kedua negara secara terbuka sudah menyatakan adanya isu-isu yang tidak dapat dirundingkan (non-negotiable issues). Pentahapan perundingan menjadi penting untuk mengendalikan perundingan seraya menghindari non-negotiable issues dan memfokuskan perundingan pada negotiable issues. Pada gilirannya, konsesi dan kesepakatan atas negotiable issues akan memunculkan sikap saling percaya dan bahkan fleksibilitas dalam perundingan yang akan berkontribusi pada keberhasilan negosiasi.

\section{DAFTAR BACAAN}

\section{Buku \& Jurnal}

Berghoff, Ethan A. \& Michael J. Fieweger (eds.), The International Negotiations Handbook: Success
Through Preparation, Strategy, and Planning (Baker \& McKenzie PILPG, nd).

Birnbaum, Ben, et al., "United StatesCuba Relations: Policy Recommendations to Advance Normalization" (2016) Graduate Policy Workshop Report.

Fandl, Kevin J., "Adios Embargo: the Case for Executive Termination of the U.S. Embargo on Cuba" (2016) SSRN.

Galluccio, Mauro, Handbook of International Negotiation - Interpersonal, Intercultural, and Diplomatic Perspectives (Springer 2015).

Hershberg, Eric \& William M. LeoGrande (eds.), A New Chapter in US-Cuba Relations Social, Political, and Economic Implications (PalgraveMacMillan 2016).

Levine, Daniel H., "What Pope Francis Brings to Latin America" (2016) 11 Center for Latin American \& Latino Studies.

Nimet Beriker-Atiyas, "An Analysis of Integrative Outcomes in the Dayton Peace Negotiations" (2001) 11 The International Journal of Conflict Management.

Ryan, Greg, US Foreign Policy towards China, Cuba and Iran - The Politics of Recognition (Routledge 2017) 


\section{Internet}

Mary Strain, Negotiation Techniques and Framing, http:/ / smallbusiness. chron . com / negotiationtechniques-framing-38785.html.

US Embassy in Cuba, https:// cu.us e mbass y.gov/ourrelationship/policy-history/ embassy-fact-sheets.

http:/ / www.managementstudyhq. com/approaches-to-negotiation. html. 
